\title{
Pigmented Fungiform Papillae of the Tongue and Lingual Fimbriae as Single Presentation in Adult: A Case Report and Literature Review
}

\author{
Meircurius Dwi Condro Surboyo ${ }^{1, \odot}$ Diah Savitri Ernawati ${ }^{1} \quad$ Adiastuti Endah Parmadiati $^{1}$ \\ Riyan Iman Marsetyo ${ }^{1}$ \\ ${ }^{1}$ Department of Oral Medicine, Faculty of Dental Medicine, \\ Universitas Airlangga, Surabaya, Indonesia

\begin{abstract}
Address for correspondence Diah Savitri Ernawati, DDS, MDS, PhD, Department of Oral Medicine, Faculty of Dental Medicine, Universitas Airlangga, Surabaya 60132, Indonesia (e-mail: diah-s-e@fkg.unair.ac.id).
\end{abstract}

Eur J Dent:2020;14:702-706

\begin{abstract}
The normal variant in the oral mucosa is a nonpathological condition. Clinical examination must be carefully performed to avoid misdiagnosis as pathological condition. We reported two rare cases of pigmented fungiform papillae and lingual fimbria.

Keywords

- dark patches

- lingual bumps

- pigmented fungiform papillae

- lingual fimbriae

- normal variant of oral mucosa Case 1 presented a 22-year-old Javanese man, with no systemic disease and several dark patches over the tongue for 2 years. Case 2 presented a 21 -year-old Javanese woman with dark patches over the dorsal and lateral of the tongue which had been known for over 4 to 5 months. Both patients had no systemic issues and there were no complaints about the patches. The dark patches, which appeared in both cases, were found together with linear small bumps on the ventral surface of the tongue and near the lingual frenulum. Further examination and specific treatment were not carried out, in accordance with the condition on the tongue.
\end{abstract}

\section{Introduction}

The normal variant in the oral mucosa is defined as a normal anatomical structure, with no pathological condition that can be found in the routine oral examination, but it can be misdiagnosed as a pathological condition. ${ }^{1}$ Median rhomboid glossitis, ${ }^{2,3}$ erythema migrants, ${ }^{4}$ hairy tongue, ${ }^{1}$ fissured tongue, ${ }^{5}$ prominence of circumvallate papilla, ${ }^{1}$ lingual varices, $^{6}$ and ankyloglossia ${ }^{7}$ are the common normal variants that can be found in the dorsum and ventral of the tongue. Other variants such as pigmented fungiform papillae of the tongue and lingual fimbriae, which are rare conditions, are not widely reported and explained in the reference.

Pigmented fungiform papillae, which appear as dark patches localized in the papillae, are a form of physiologic pigmentation. It needs to be explained and described in more detail, as this condition may be confused with malignant pigmented lesions. ${ }^{8}$ This condition is commonly observed among the dark-skinned people. ${ }^{9}$

Lingual fimbria, which also considered a normal variant, may be the result of alteration of the growth of the tongue. It appears as small papules or bumps on the ventral surface and at the side of the lingual frenulum. There are limited references that can explain this condition, and it is sometimes confused with squamous papilloma or oral warts. ${ }^{1}$

This case reported dark patches and lingual bumps on the tongue, considered as pigmented fungiform papillae and lingual fimbriae, in the young adult Javanese male and female. This case report emphasizes the clinical features of combined pigmented fungiform papillae and lingual fimbriae as a rare entity, not usually found in the routine intraoral examinations. We presented this case to provide information to 
clinicians, in order for them to be able to recognize this condition and conduct proper management, as it is rare and may resemblance other pathology, rendering misdiagnosis and overtreatment.

\section{Cases}

\section{Case 1}

A 22-year-old Javanese man, with no systemic disease, came with several dark patches over his tongue. Intraoral examination showed multiple asymptomatic macula, which were brownish-black and shared clear border over the dorsolateral sinistra and dextral of the tongue ( - Fig. 1A). Small

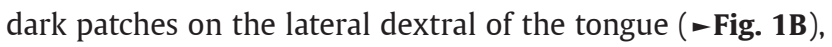
and large dark patches on the lateral sinistra of the tongue

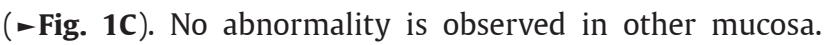
The patient had this condition for 2 years, but there were no other symptoms associated with the patches such as pain, numb, tingling, or burning sensation. The ventral surface of the tongue showed hairy-like papules, laterally making a line to the lingual veins, which were red in color and asymptomatic. Some of them appeared as minor "bumps" (-Fig. 1D and 1E).

The patient did not smoke, chew tobacco, or consume alcohol alcohol but was fond of spicy foods. The physical examination indicated obesity with body mass index (BMI) of 41.52. Within a year of routine oral health examination, no drugs or treatment could remove the patches. The family history review showed that the dark patches over the tongue did not appear in other family members. The condition on the dorsolateral surface of the tongue can be identified as pigmented fungiform papillae and the ventral surface of the tongue can be identified as lingua fimbriae.
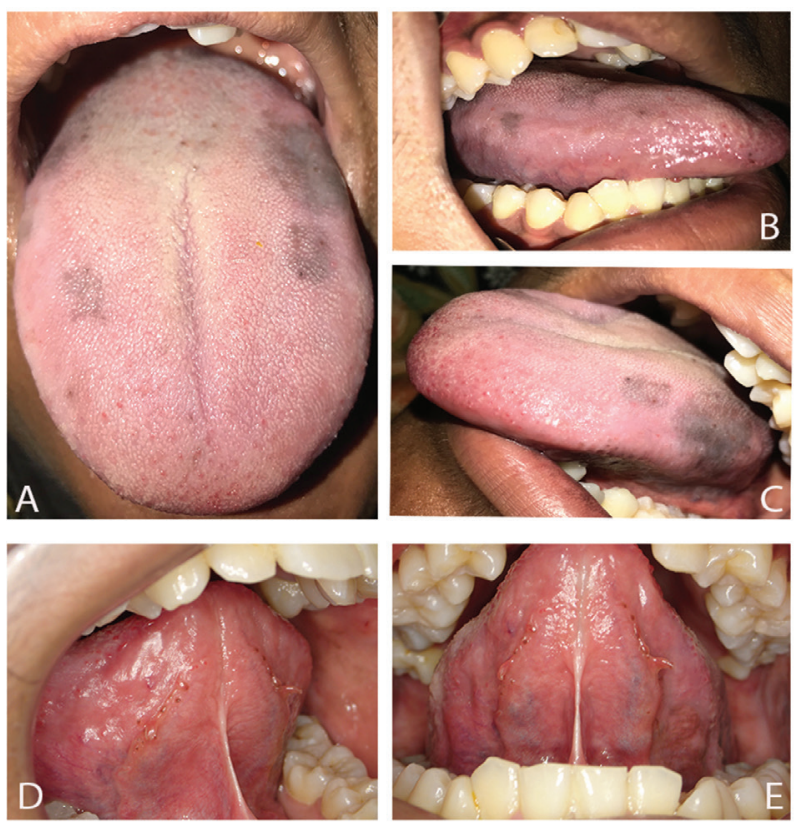

Fig. 1 Multiple brownish-black patches over the dorsal (A), lateral dextral (B), lateral sinistra (C), and asymptomatic hairy-like or bumps on ventral surface of tongue (D, E).

\section{Case 2}

A 21-year-old Javanese woman came with dark patches over the tongue which had been known for over 4 to 5 months. Dorsolateral examination of the tongue showed multiple brownish-black, diffuse, and asymptomatic macula, (-Fig. 2A). These patches appeared over the posterior and anterior dorsal surfaces of the tongue; also, they came with dark brown prominent papilla on the lateral surface ( - Fig. 2B, 2C). The ventral surface of the tongue showed multiple papules on the medial and lateral lingual veins. These papules appeared light red in color with hair-like shape, but some of them had a minor "bumps" shape, which mainly appeared beside the lingual frenulum ( - Fig. 2D, 2E).

The patient had routine oral examination along with orthodontic treatment, and she had no complaints about the patches. Because of the asymptomatic condition, no treatment or drugs were used to treat the tongue. The physical examination showed the normal BMI was 24.78. The patient was prescribed meloxicam over the past 5 months for condyle arthritis, and no systemic disease was diagnosed. The patient did not smoke, chew tobacco, or consume alcohol but was fond of spicy foods. No abnormality was observed in other mucosa. Other family members had no patches on the surface of their tongue. The condition on the dorsolateral surface of the tongue can be identified as pigmented fungiform papillae and the ventral surface of the tongue can be identified as lingua fimbriae.

\section{Management}

In our cases, biopsy for histological examination and other supporting assessment were not performed, because there were no complaints from the patients. So, we considered them as normal variants of oral mucosa from the history,

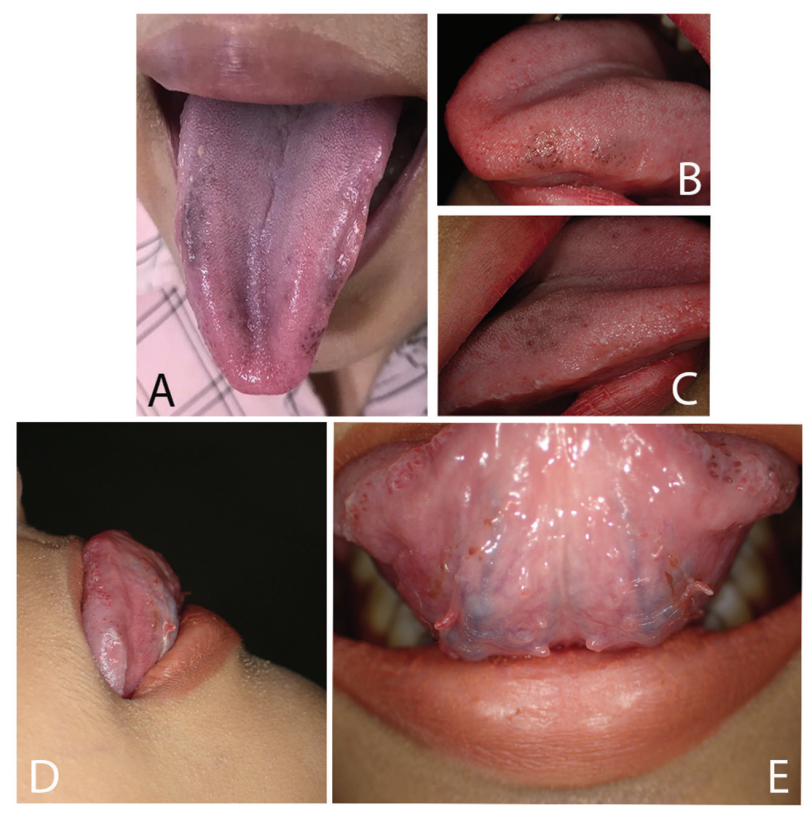

Fig. 2 Multiple brownish-black patches over the dorsal (A), lateral dextral (B), lateral sinistra (C), and asymptomatic multiple bumps on the ventral surface of the tongue (D, E). 

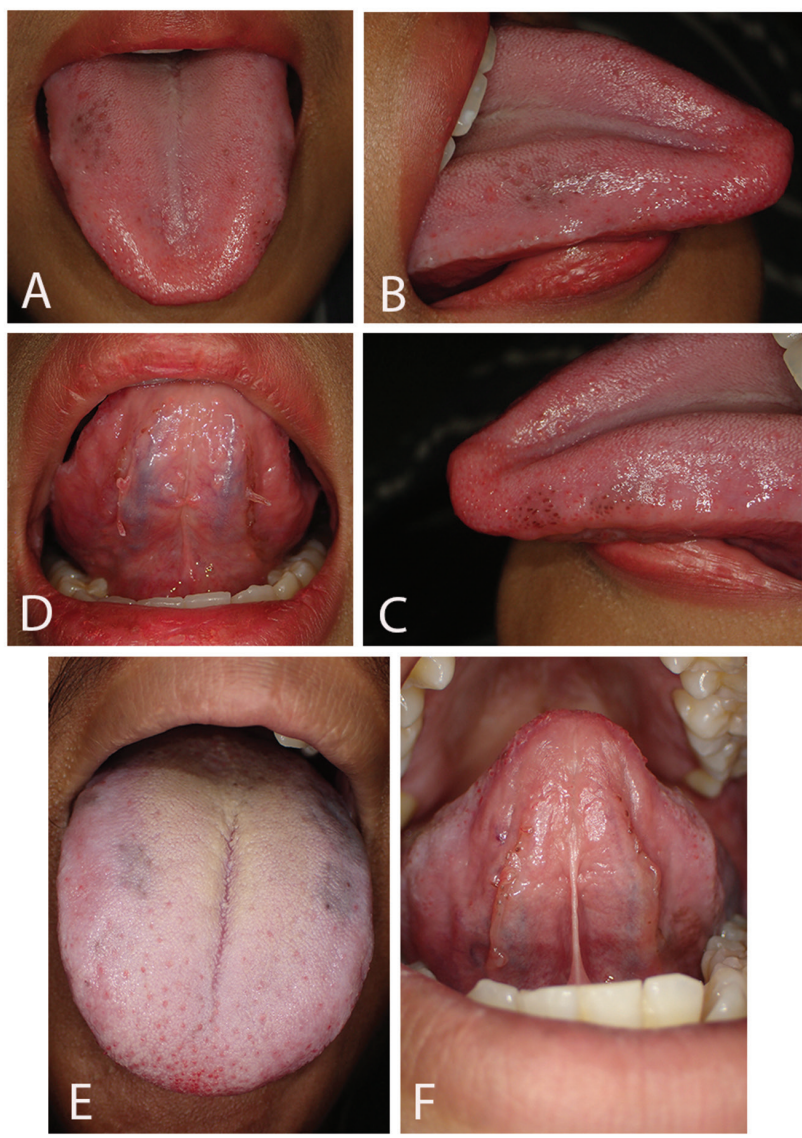

Fig. 3 The follow-up 6 months later. The patches over the dorsal of the tongue (A), lateral dextral (B), lateral sinistra (C), and bumps on ventral of the tongue (D) (female patient). The patches over the dorsal (E) and bumps on ventral of the tongue (F) (male patient).

anamnesis, and clinical appearance. There was no treatment conducted in both cases, because we found no complaints lodged by these patients about their respective conditions. Information and education about the patches and bumps were provided to the patients.

\section{Follow-up}

As there was no treatment conducted in these cases, outcomes were not observed, and follow-ups were not scheduled. We advised the patients to visit a clinician if they have complaints associated with the patches and the bumps on the tongue. Six months later, the condition of the patches and bumps on the tongue turned out to be identical to the first condition. No other conditions and clinical changes were observed in case 1 (-Fig. 3A-D) and case 2 (-Fig. 3E, F).

\section{Discussion}

Diagnosis of pigmented lesions of the oral mucosa and perioral is challenging. Generally, the clinical aspects of oral mucosa pigmented lesions are sufficient in establishing the diagnosis. However, in some cases, biopsy is necessary and, occasionally, for histology and immunohistochemical stains such as melan-A and S-100 protein, it may be required to prompt a correct diagnosis. ${ }^{10}$ In cases of pigmented papillae fungiform, sometimes, biopsy is not needed. The diagnosis can be based on typical clinical features. Most cases reported the pigmented papillae fungiform diagnosis established on the basis of clinical features as presented in - Table 1. Most cases were found in women and affected the anterior and lateral borders of the tongue. The clinical appearance of the macula ${ }^{11}$ was multiple hyperpigmented papillae,, with round or polygonal pattern, and presenting with diffuse margins. ${ }^{9}$

In most of the reports, pigmented papillae fungiform were found in dark-skinned children or young adults. ${ }^{12}$ Cases of pigmented papillae fungiform are still not widely reported in Asia. The first pigmented papillae fungiform was reported in Asia by Scarf and Marks (2003), ${ }^{13}$ and then by Tan et al (2014) among the Chinese. ${ }^{14}$ In our cases, the pigmented papillae fungiform were found in a young Javanese man and woman with white skin.

The pigmented papillae fungiform condition undergoes physiological pigmentation. The dermoscopy shows several projections with hyperpigmented papillae resembling rose petal pattern ${ }^{15}$ or cobblestone pattern. ${ }^{14,16}$ Rose petal pattern was found in $39.66 \%$, and cobblestone pattern in $100 \%$, of female and male Chinese. ${ }^{14}$ In our cases, both patients showed a cobblestone pattern. The pattern of pigmentation in our cases was found in the dorsolateral surface of the tongue (Case 1) and involving three to seven fungiform papillae in the lateral and anterolateral surfaces of the tongue (Case 2). Based on classification, Case 1 is type 2 of pigmented papillae fungiform, and Case 2 is type 1 of pigmented papillae fungiform. In some of the literature, the classification of pigmentation consists of three types. Type 1 is characterized by well-defined hyperpigmented of fungiform papillae on the anterolateral side and tip of the tongue. Type 2 has hyperpigmentation involving three to seven few fungiform papillae over the dorsal surface of the tongue. Type 3 is hyperpigmentation of all fungiform papillae on the dorsum of the tongue. ${ }^{11,17}$

Histological examinations were not performed in our cases because there were no complaints. This condition is also found in other cases, but histological examination of the case of pigmented fungiform papillae was not performed. Robles-Méndez et al (2017) reported histological examination revealed pigmentation in the basal layer of papillae and melanophages in the lamina propria, ${ }^{18}$ and in other cases showed slight lymphocytic infiltrate in the superficial. ${ }^{19}$

The general or systemic condition may have connection with pigmented papillae fungiform. Karine Francine Docx et al (2016) mentioned that pigmented papillae fungiform can be found in obese children with an earlier menarche (higher level of estrogen). ${ }^{20}$ One of our cases also present in a young obese (higher BMI) individual, but the other case presented normal BMI.

Our cases are unique that is, the pigmented papillae fungiform found accompany lingual fimbriae. Lingual fimbriae are the papules, laterally making a line to the lingual veins and lingual frenulum. Lingual fimbriae may be a result of incomplete apoptosis of the ventral surface of the tongue. The tongue originates from the first, second, and third pharyngeal 
Table 1 The reported of pigmented papillae fungiform

\begin{tabular}{|c|c|c|c|c|c|c|}
\hline No. & Gender & Ages & Races & $\begin{array}{l}\text { Location of affected } \\
\text { papillae }\end{array}$ & Clinical appearance & Reference \\
\hline 1 & Women & 40 & Black & Anterior of the tongue & $\begin{array}{l}\text { Multiple hyperpigmented papillae, with pattern rose } \\
\text { petal appearance }\end{array}$ & 2 \\
\hline 2 & Women & 44 & African & Anterior of the tongue & $\begin{array}{l}\text { Multiple hyperpigmented papillae, with round or } \\
\text { polygonal shape }\end{array}$ & 5 \\
\hline 3 & Women & 12 & African & $\begin{array}{l}\text { Anterior, lateral, and } \\
\text { dorsum of the tongue }\end{array}$ & $\begin{array}{l}\text { Multiple hyperpigmented papillae, presented as } \\
\text { dark patches }\end{array}$ & 8 \\
\hline 4 & Women & 30 & Black & Anterior of the tongue & $\begin{array}{l}\text { Multiple hyperpigmented papillae, with pattern rose } \\
\text { petal appearance }\end{array}$ & 9 \\
\hline 5 & Women & 13 & Mexican & Anterior of the tongue & $\begin{array}{l}\text { Multiple hyperpigmented papillae, with pattern rose } \\
\text { petal appearance }\end{array}$ & 6 \\
\hline 6 & Women & 13 & South Asian & Anterior of the tongue & $\begin{array}{l}\text { Light to dark brown pigmentation, round or } \\
\text { polygonal in shape, circumscribed to the papillae, } \\
\text { and resembling a cobblestone appearance }\end{array}$ & 7 \\
\hline 7 & Women & 12 & Moroccan & Anterior of the tongue & $\begin{array}{l}\text { Multiple hyperpigmented papillae, present in a } \\
\text { diffuse and symmetrical pattern }\end{array}$ & 10 \\
\hline 8 & Man & 36 & Indian & $\begin{array}{l}\text { Anterior and lateral of } \\
\text { the tongue }\end{array}$ & $\begin{array}{l}\text { Multiple hyperpigmented papillae, present in a } \\
\text { symmetric distribution }\end{array}$ & 11 \\
\hline 9 & Women & 25 & Saudi & $\begin{array}{l}\text { Anterior and lateral of } \\
\text { the tongue }\end{array}$ & $\begin{array}{l}\text { Brown macula with diffuse margins with multiple } \\
\text { hyperpigmented papillae }\end{array}$ & 4 \\
\hline 10 & Women & 23 & $\begin{array}{l}\text { Not } \\
\text { reported }\end{array}$ & $\begin{array}{l}\text { Anterior and lateral of } \\
\text { the tongue }\end{array}$ & $\begin{array}{l}\text { Multiple hyperpigmented papillae, which are pres- } \\
\text { ent in a diffuse pattern }\end{array}$ & 12 \\
\hline 11 & Women & 29 & $\begin{array}{l}\text { Not } \\
\text { reported }\end{array}$ & $\begin{array}{l}\text { Anterior, lateral, and } \\
\text { dorsum of the tongue }\end{array}$ & $\begin{array}{l}\text { Multiple hyperpigmented papillae, presented in a } \\
\text { diffuse and symmetrical pattern }\end{array}$ & 13 \\
\hline 12 & Man & 11 & $\begin{array}{l}\text { Black } \\
\text { Brazilian }\end{array}$ & $\begin{array}{l}\text { Anterior and lateral of } \\
\text { the tongue }\end{array}$ & Multiple hyperpigmented papillae & 14 \\
\hline
\end{tabular}

arches and develops at the beginning of the fourth intrauterine week. ${ }^{21}$ During this phase, a deep sulcus develops in front of and on both sides of the tongue which gives the tongue its mobility. ${ }^{22}$ Normally, apoptosis separates the tongue from the floor of the mouth, and the only tissue that remains to anchor the tongue to the mouth floor is the frenulum. ${ }^{23}$ The incomplete apoptosis in the ventral surface of the tongue results a normal residual tissue not completely reabsorbed by the body during the development and growth of the tongue and which is called lingual fimbriae. ${ }^{24}$

There are few studies about lingual fimbriae, especially in pathogenesis and clinical presentation. Both pigmented fungiform papillae lingual fimbriae of the tongue were considered normal variants, with no positive correlation to each other in development and incidence. Lingual fimbriae appear as the result of incomplete cell apoptosis, while pigmented fungiform papillae are associated with pigmentation disorder. At present, there are no findings that show interrelated causes in both conditions.

Pigmented fungiform papillae and lingual fimbria were considered normal variants, and they were not malignant or any condition that is threatening. No specific treatment is needed, but further investigation should be done by clinicians if there are progressive changes or significant complaints from patients. Knowledge and ability to identify those clinical appearances are key to the management of both cases because of the rareness and the resemblance of the clinical features with more serious pathology, rendering misdiagnosis and overtreatment. Further studies need to be done to investigate if there is association between pigmented fungiform papillae and lingual fimbriae of the tongue besides the clinical aspects.

\section{Ethical Approval}

All procedures performed in this study were in accordance with the ethical standards of the Institutional Research Committee and the Declaration of Helsinki 1964 and its later amendments or comparable ethical standards. Informed consent was obtained from the patients whose cases were reported in this study.

\section{Funding}

None.

\section{Conflict of Interest}

None declared.

\section{References}

1 della Vella F, Lauritano D, Lajolo C, et al. The pseudolesions of the oral mucosa: differential diagnosis and related systemic conditions. Appl Sci (Basel) 2019;9(12):2412

2 Goregen M, Miloglu O, Buyukkurt MC, Caglayan F, Aktas AE. Median rhomboid glossitis: a clinical and microbiological study. Eur J Dent 2011;5(4):367-372

3 Surboyo MDC, Ernawati DS, Parmadiati AE. Glossitis mimicking median rhomboid glossitis induced by throat lozenges and refreshment candies. J Int Oral Health 2019;11(5):323-328 
4 Chaubal T, Bapat R. Geographic tongue. Am J Med 2017; 130(12):e533-e534

5 Sudarshan R, Vijayabala GS, Samata Y, Ravikiran A. Newer classification system for fissured tongue: an epidemiological approach. J Trop Med 2015;2015:1-6

6 Akkaya N, Ölmez D, Özkan G. Evaluation of the factors associated with sublingual varices: a descriptive clinical study. Folia Morphol (Warsz) 2019;78(2):325-330

7 Hong P. Five things to know about...ankyloglossia (tongue-tie) CMAJ 2013;185(2):E128

8 Mukamal LV, Ormiga P, Ramos-E-Silva M. Dermoscopy of the pigmented fungiform papillae of the tongue. J Dermatol 2012;39(4):397-399

9 Lake PL. Dark spots on the tongue. J Dermatol Nurses Assoc 2017;9(3):146-147

10 McCarthy C, Holt D, Triantafyllou A. Solitary pigmentation of the tongue: lentigo simplex or pigmented fungiform papilla? Oral Surg 2016;11(1):50-54

11 Alzahrani N, Alharithy R. Pigmented fungiform papillae of the tongue in a Saudi woman. J Dermatology Dermatologic Surg. 2018;22(1):39

12 Aqil N, Bennani M, Nassiri A, Meziane M, Gallouj S, Mernissi FZ. Pigmented fungiform papillae of the tongue: clinical and dermoscopic features. Our Dermatology Online 2019; 10(2):213-214

13 Scarff CE, Marks R. Pigmented fungiform papillae on the tongue in an Asian man. Australas J Dermatol 2003;44(2):149-151

14 Tan C, Liu Y, Min ZS, Zhu WY. A clinical analysis of 58 Chinese cases of pigmented fungiform papillae of the tongue. J Eur Acad Dermatol Venereol 2014;28(2):242-245
15 Castellanos MAR, Echeverria AEB, Rosas GMA. Dermatoscopía en la pigmentación de papilas fungiformes de la lengua. Dermatologia Cosmet Medica y Quir 2018;16(3):206-207

16 Pinos-León V. Dermoscopic features of pigmented fungiform papillae of the tongue. Actas Dermosifiliogr 2015;106(7): 593-594

17 Romiti R, Molina De Medeiros L. Pigmented fungiform papillae of the tongue. Pediatr Dermatol 2010;27(4):398-399

18 Robles-Méndez JC, Ayala-Cortés AS, Villarreal-Martínez A, Ocampo-Candiani J. Dermoscopy of pigmented fungiform papillae of the tongue. J Am Acad Dermatol 2017;76(2S1): S40-S42

19 Ghigliotti G, Chinazzo C, Parodi A, Rongioletti F. Pigmented fungiform papillae of the tongue: the first case in an Italian woman. Clin Exp Dermatol 2017;42(2):206-208

20 Karine Francine Docx M, Vandenberghe P, Govaert P. Pigmented fungiform papillae of the tongue (PFPT) Acta Clin Belg 2016;71(2):117-118

21 Hong SJ, Cha BG, Kim YS, Lee SK, Chi JG. Tongue growth during prenatal development in Korean fetuses and embryos. J Pathol Transl Med 2015;49(6):497-510

22 Felemban R, Mawardi H. Congenital absence of lingual frenum in a non-syndromic patient: a case report. J Med Case Reports 2019;13(1):56

23 Magreni A, May JG. Embryology of the oral structures. Oper Tech Otolaryngol--Head Neck Surg 2015;26(3):110-114

24 Pompéia LE, Ilinsky RS, Ortolani CLF, Faltin K. Ankyloglossia and its influence on growth and development of the stomatognathic system. Rev Paul Pediatr 2017;35(2):216-221 